\title{
Discussions about Health Insurance in Holland
}

\author{
by G.W. de Wit*
}

This note is intended to present the issues which will come up for discussion in the near future in the Netherlands in the field of health care.

During the previous period of government the costs of health care were cut down. This primarily led to a profound change in the manner of financing. Measures were taken which even today continue to affect insurers in the process of implementation. In the field of social care hardly anything has changed.

When the present Cabinet took office, it was again announced that the cost of health care should be cut down further. By that time a certain stabilization of costs had been achieved. At present the cost of health care in the Netherlands constitutes $8.4 \%$ of the GNP.

To find a way in which the costs should be cut back further, a committee was appointed under the chairmanship of former Philips top executive Dekker. This committee's assignment went further than just drawing up a recommendation with regard to the cutbacks. The committee was asked to develop a long-term plan because there was a widespread concern about the future cost and accessibility of health care, particularly on account of recent technological developments and the fact that the population, on the average, is getting "older".

Right from the start it was clear that this committee would come up with some far-reaching proposals, and many groups from the field hastened to formulate their own ideas. Even before the report of the Dekker Committee was presented, the ideas of the major political parties, of a number of government advisory boards and of various organized groups had already been formulated.

When the plan finally appeared, it did indeed contain a number of revolutionary ideas which naturally evoked a wide range of reactions, from "very fine", "courageous" to "totally unfeasible". There was one thing everyone did agree on however and that was that here for the first time an extremely coherent report had been written on the subject of health care, including social services, its financing and its objectives. What does the report actually say?

The major scheme throughout the report is the introduction of a market mechanism i.e. an element of competition. Economic forces must ensure that the best possible supply is offered, particularly as far as quality is concerned, at the lowest possible price, and in the freeest possible market.

\footnotetext{
${ }^{*}$ Adviser Research, Nationale-Nederlanden, Rotterdam
} 
How does the committee propose to achieve this?

First of all, the committee believes that a thorough revision of the financing system is necessary. This charge therefore comes virtually on top of the earlier drastic change in 1986. Why? In this way they want to create one single flow of money to allow the competitive element to have ist full effect.

The basic idea in the Committee's plans is the elimination of the dividing line between state health insurance funds and private insurers. In practice, this means that both categories will be active as insurers in the market to the same degree. This is intended to bring about one flow of money, as mentioned earlier.

Since such a far-reaching change in the manner of financing profoundly affects insurers and is of vital importance to them, I would first of all like to give you a brief sketch of the Committee's proposals on this point.

The state health insurance package, which virtually contains all provisions, together with the Exceptional Medical Expenses (AWBZ) provisions and the social services will be reduced to $85 \%$ of its present size. This means that all medicines, physiotherapy and a number of minor treatments will be removed from the package. This $85 \%$ basic package will be obligatory for every Dutchman. This is scarcely anything new, since practically everybody is already insured against medical expenses.

The financing of this basic package is done partly on a percentage basis and partly on a nominal basis. Around $75 \%$ of the package is financed with a percentage premium, amounting to $4,2 \%$ of the income on a maximum of DFls 64,550 . The rest is levied on a nominal basis. The implementation is rather complicated and in the Dekker Committee's report it is not described very clearly. The percentage premium is collected by the tax authorities and paid into a Central Fund. From this Central Fund the insurers then receive a fixed amount which is based on the age and state of health of the insured.

In addition to this basic package every insurer offers, on a voluntary basis, a complementary package which includes, among other things, medicines and physiotherapy. A fixed premium is charged for this. Both for the basic package and for the complementary package the insurers have an obligation to accept all applicants.

In this way the Committee believes that one flow of money will be created, in which so much fixed premium plays a role that a significant market effect will come about. As a matter of fact, it is only this fixed part on which competition, and therefore market effect, is possible.

They want to strengthen the element of competition even further by offering the possibility to select a number of deductibles.

Now we come to the subject of the provision of services. In this area not very much has happened in the past years. Since the government sets the rates, the number of treatments provided in the hospitals, as well as the number of physicians who are allowed to practise, costs have remained stable, partly because inflation was nearly zero. This made it impossible for costs to rise further, but at the same time this meant that the costs could not go down either. Such measures as reducing the number of hospital beds resulted in higher rates for hospital care, since the rates and volume were fixed (= budgets). 
The Committee proposes to abandon this rigid scheme and to replace it by regulations setting maximum rates. When consequently hospitals, physicians and other providers of services are free to determine their own rates, then it is the intention that each insurer enters into an agreement with each provider of services, hospital, physician, etc., on the most favourable conditions, taking into account the quality of the services provided. In this way it is hoped that due to the operation of the market mechanism and the large surplus of hospital beds and physicians, costs will go down automatically. The control of the quality of the health care services will remain the responsibility of the government. By entering into such agreements, it is also hoped that a number of incentives will be built in to avoid treatment at a more expensive level: less referrals by the general practitioner to the specialist, less hospitalizations, the most efficient choice between hospital, nursing home, senior citizens home and home care. This all falls under the heading of a directed substitution policy.

This is the reason why in this report for the first time health care and social services have been discussed together.

Thus far I have briefly given you some idea of the undoubtedly revolutionary proposals which this Committee came up with. Now the question is: what does the public in general think about this? It would go too far to mention all the different reactions here. However two of these reactions seem to me to be significant:

1. How do the government and political parties react to this?

2. What is our own opinion, as insurers, with regard to this report?

In the beginning we already mentioned that even before the report had been submitted by the Dekker Committee, the political parties had already formulated their ideas about this problem in their own brochures.

In the report of the Liberals an approach is chosen which is very similar to the one we find in the Dekker Committee Report. Although they differ somewhat on several points, the major tenet is the same. One thing is very clear in the Liberals' position: in order to activate the competitive element in the market, they support the introduction of HMO's following the American example. A position which has not been adopted by the Committee.

The Christian Democrats prefer a more gradual approach, particularly with regard to the financing. They endorse the idea of the market mechanism, but they do not consider it necessary in the short term to drastically change the system of financing. They feel that this should be done gradually, in several stages, and they would first of all want to give the health insurance funds the freedom to negotiate more, a freedom which does not exist at the present time, and would then, if necessary, want to adjust the private market. In the long-term they would want to bring the merging of health insurance funds and private insurers up for discussion in order to come to one totality, one flow of money, just as the Dekker Committee proposed.

The Social Democrats have a plan which is inherent in their own philosophy: a national social insurance. In the case of a virtually complete insurance package they want the part of the total premium income which is generated by fixed premiums, to be limited to $5 \%$.

After the Committee's report first appeared, the government was enthusiastic about the ideas laid down in the report. 
It turns out however, that if this new way of financing would be introduced, the consequences for people's incomes would be considerable, that the ideas of a Central Fund would be difficult to implement and that one could ask the question whether the new provisions, such as care for the mentally handicapped, care for the elderly and home care can also be handled by private insurers in an acceptable manner from the insurers' point of view. Moreover further questions arise: all medicines would be covered under a voluntary complementary package (there is a general concern that especially those in the low income bracket will not take out this complementary insurance. This would be in conflict with the Constitution which stipulates that every Dutchman has a basic right to health care).

Furthermore, if the new plan as proposed by the Committee would be introduced, this would result in a sizable deficit in the financing of the General Old Age provision and in the Budget.

In order to get some idea of what people in the field think about this, in the beginning of May the government held a number of public hearings in which everyone from the field, both providers of services and insurers, was given an opportunity to make their position on this report known.

What is our opinion?

Basically we fully endorse the idea of the market mechanism, although we are afraid that the idea of individual agreements between each insurer and each provider of services will be impracticable. The more each side forms one block, the less the market mechanism will work. We can also go along with the integrality of the report, although it will require a great deal of study to gain some insight into the question as to how we will have to handle the new provisions which until now were not considered to be part of health care.

We are far less happy with the proposed system of financing. We do recognize the necessity of one flow of money, but we see this more in a vertical sense, encompassing all types of care, from the general practitioner to the home for the elderly. Why this flow of money must also be realized horizontally, that is to say, by maintaining the elimination of the division between health insurance funds and private insurers, is less clear to us. Precisely by this elimination a certain amount of competition would be taken away. Moreover we are afraid that the premium on a percentage basis will constitute an impediment for private insurers to give the idea of a market mechanism optimal form. As a matter of fact, the Dekker Committee sets a condition to make the market mechanism work: the percentage part is to be as large as possible, and let's not forget that the present privately insured (approximately $40 \%$ of the population) pay an entirely fixed premium, which in the new situation would for the major part be replaced by a premium based on a percentage of the income.

We therefore consider a test of the operation of the market mechanism, on the condition that the prescribed rates for health care are eliminated, very well possible, starting from the present situation, that is to say; by maintaining the division between health insurance funds and private insurers, whereby in the future it will have to be investigated further in what way the financing should, if necessary, be adjusted.

In this brief summary, among other things, ideas have been expressed about the possible introduction in our country of certain methods applied in the United States. We are particularly thinking here of the HMO's (Health Maintenance Organizations). Are such methods also expected to be introduced in the Netherlands? 
In the United States HMO's were primarily introduced for large enterprises. In our country we do not have such large groups. Under the system of HMO's, at a lower premium, there is no free choice of physician or hospital. Here again we are wondering whether this would really be suitable for the Netherlands.

Nevertheless one has to note that a great affinity with the introduction of a market mechanism exists in the Netherlands. Are other forms being considered?

The system of PPO's (Preferred Provider Organizations) fits in better with our ideas. These PPO's offer a (limited) free choice of physician and hospital. A further difficulty is that agreements with a (very) large number of hospitals must be made (most Dutch health insurers operate nationwide). We have already pointed this out.

Apart from the present legal problems which need to be worked out, it seems to me that the introduction of HMO's or PPO's is not possible right away. Also in the United States most persons still continue to be insured in the traditional manner (triple option). Moreover we are afraid that due to the introduction of HMO's and PPO's a certain risk selection will take place, which we do not consider desirable.

Of the various methods used in the United States we expect the most of "managed care", that is to say, the type of agreements, control of the diagnosis (Diagnostic Related Groups), control of the use of hospital beds, substitution of the care used, "second opinion", etc.

After this outline of the present situation in the Netherlands, I would like to make two general remarks.

At the present time people are either insured under the social insurance (with a private additional insurance) or privately insured, in some cases under both types of insurance at the same time (as in England). In most countries the social insurance predominates and in many cases it covers the entire population.

In many countries, also in those where nearly everyone falls under the social insurance, there is a tendency towards privatization (for parts of the social insurance package or for the entire social insurance package but this is only for certain groups of persons). In this process of privatization the government is still afraid to transfer everything right away to the private insurance industry. After all health insurance must be and continue to be available to everyone at an acceptable price. Therefore certain government requirements have to be satisfied by the private insurance industry before the transfer can take place.

These government regulations do however imply certain dangers. Here I quote three statements from an article by Mr. Ramey entitled "Notes on the theme: The complementary function of private health insurance to the state scheme", which appeared in Etudes et Dossiers, no 111, p. 89 ff.:

- Enabling legislation for private managed health insurance plans;

- Through licensure, retain social reponsibility for quality of service, fiscal stability of competitive private plans;

- Create a regulated market that assures fair competition relative to price and quality of service. 
This leads me to my first fundamental question: To what extent is the private insurance being controlled and restricted? The danger is not imaginary that this happens first for health insurance, and subsequently for other classes of business (in the Netherlands $40 \%$ of the total non-life premium volume relates to health insurance).

Another possibility to bring about cost control and privatization is the HMO.

This brings me to the next question. Who is in this case the insurer: the private insurer or the hospital (or a chain of hospitals)? In the United States there already exists a separate legislation on this point (in D.G. Green: "Challenge to the NHS" (London, 1986), on p. 73 a separate paragraph is devoted to this problem under the title "Hospitals as Insurers"). In the Netherlands certain groups are already speaking of a changeover from classical insurer to health care insurer, even to financier of the health care.

Therefore my second question is: To what extent will the role of the insurer as spreader of risks continue to exist in the near future and if not (fully or partially), will this spread to other classes of business (for example, what is the difference between a chain of hospitals and a chain of service stations)?

In summary: Are we on the right course with our measures to cut down the costs in a specific class of business - as here in the case of health insurance following the American example - to ensure a healthy future for the total private insurance? 